\title{
Modeling Static VAR Compensators Using Adaptive Neural Network
}

\author{
Salem AlKhalaf, Osama Alfarraj, and Ashraf Mohamed Hemeida \\ Computer Science Department Ar-Rass College of Science \& Arts Qassim University, Saudi Arabia \\ s.alkhalaf@qu.edu.sa \\ Computer Science Dept. Community College, King Saud University Saudi Arabia \\ oalfarraj@ksu.edu.sa \\ Computer Science Department Ar-Rass College of Science and Arts Qassim University, Saudi Arabia \\ ahemeida@yahoo.com
}

\begin{abstract}
The artificial neural networks is applied successfully for modeling any systems where these systems deals with input/output data. This paper implement the artificial neural network (ANN) for modeling static var compensators (SVC) connected to single machine infinite but power system with local load. The system is modeled using nonlinear differential and algebraic equations. The SVC received an input signal to deliver or absorb the reactive power from the network based on the system status. The input signal to the SVC is derived based on any controller. The structure of the ANN model is derived based on the system dynamic performance. Different operating conditions is considered to assure enough number of data to train the neural network model. An adaptive function has been added to ANN network, to ensure robust and high response of the proposed model. The Matlab software is used for the time simulation of the proposed system. The obtained results indicate the ability of the derived model of the SVC based ANN in improving the system dynamic performance and damping the power systems oscillations very fast with better control quality.
\end{abstract}

Keywords: Adaptive neural network - Modeling - Static VAR Compensators (SVC).

\section{Nomenclature}

$\omega_{0} \quad$ the rated rotor electrical speed in $\mathrm{rad} / \mathrm{sec}$

$\omega_{\mathrm{s}}$ the rotor synchronous speed in $\mathrm{rad} / \mathrm{sec}$.

$\delta$ the rotor angle in rad.

$\mathrm{R}_{\mathrm{fd}} \quad$ the field circuit resistance in p.u.

$X_{d}$ the direct axis synchronous reactance in p.u.

$X_{q}$ the quadrature axis synchronous reactance in p.u.

$X_{d}$ the direct axis transient reactance in p.u.

$X_{q}{ }^{\prime}$ the quadrature axis transient reactance in p.u.

$\mathrm{T}_{\mathrm{A}}$ the amplifier time constant in p.u.

$\mathrm{K}_{\mathrm{A}}$ the amplifier gain.

$\mathrm{K}_{\mathrm{E}}$ the self excited constant.

$\mathrm{T}_{\mathrm{E}}$ the self excited Time constant.

$V_{R}$ the regulator output voltage in p.u.

$\mathrm{S}_{\mathrm{E}}$ the function of excitation level in p.u.

$\mathrm{E}_{\mathrm{fd}}$ the Exciter output voltage in p.u.

$\mathrm{E}_{\mathrm{q}}{ }^{\prime}$ the quadrature axis transient voltage in p.u.

$\mathrm{E}_{\mathrm{d}}$ the direct axis transient voltage in p.u.

$\mathrm{V}_{\text {ref }}$ the reference input voltage in p.u.

$\mathrm{V}_{\mathrm{t}}$ the terminal voltage in p.u.

$\mathrm{H}$ the inertia constant in sec.

$\Delta w_{i j}(\mathrm{t})$ The weight change from a neuron in the $\mathrm{i}^{\text {th }}$ layer to the neuron in the $\mathrm{j}^{\text {th }}$ layer

$\mathrm{O}_{\mathrm{jp}}$ The network output in the $\mathrm{j}^{\text {th }}$ unit in the output layer for a pattern $\mathrm{p}$.

$\mathrm{T}_{\mathrm{jp}}$ Target value in the training pattern

$\mu$ The learning rate 
$w_{i j}$ The weights from layer i to layer $\mathrm{j}$

$\beta$ The momentum factor

$\mathrm{t}$ The iteration number

$\theta_{j}$ The bias for the layer $j$

F The sigmoid activation function.

\section{Introduction}

The SVC is one of the most important FACTS devices which are very effective for voltage regulations and stability improvement of the power systems. Due to the extensions of the power networks the use of SVC became very essential. Fixed capacitors, Thyristor control reactors static VAr Compensators SVC are used worldwide for utilities purposes. The main objective of inserting such SVC systems is to regulate the node voltages at weak points of the utility grid as well as maintaining the voltage stability of industrial loads, and improving the power system dynamic performance in case of abnormal operating conditions [1-6]. The Improving such models can provide a very good response to the whole system. Modeling electric devices take place to define how can these devices be modified. Different techniques have been used for modeling many electric devices[7-11]. The ATP-EMTP software is used for modeling the synchronous generator excitation and governor on an interconnected power system[12]. The artificial neural network is applied successfully for solving the steady state power flow of electric power systems[10]. The use of ANN in solving the steady state power flow is superior over the conventional Newton-Raphson method. A reduced order artificial neural network is implemented for modeling the external part of electric power systems dynamic. They use the data obtained from random disturbance to evaluate the model[13]. The application of artificial neural network in modeling and simulation of different properties of engineering materials, are presented and investigated[14]. artificial neural network (ANN) is employed to predict steam-assisted gravity drainage production in heterogeneous reservoirs. Numerical flow simulations are performed to construct a training data set consists of various attributes describing characteristics associated with reservoir heterogeneities and other relevant operating parameters[15]. The artificial neural network (ANN) models have been used for representing and modelling the velocity distributions of combined open channel flows. ANN models are established and examined using data derived from computational-fluid-dynamics models. The ANN model training strategy is obtained for reducing the main uncertainty source[16]. ANN is gaining popularity as a tool, which can be successfully used for the thermal analysis of heat exchangers with acceptable accuracy. The investigation of implementing ANN for thermal analysis of heat exchangers are reported for modeling of heat exchangers, estimation of heat exchanger parameters, estimation of phase change characteristics in heat exchangers and control of heat exchangers[17]. This work introduces joint power amplifier (PA) and I/Q modulator modeling and compensation for Long Term Evolution (LTE) transmitters using artificial neural networks (ANNs) have been introduced and investigated[18]. The artificial neural networks (ANNs) are implemented to predict the power factor and torque of wind turbines based on the collect3ed experimental data. The data collected for seven prototype vertical Savonius rotors tested in a wind tunnel. The rotors with different configurations were located in the wind tunnel and the tests were repeated 4-6 times in order to reduce errors[19]. Multi-variable least square based empirical correlations and artificial neural network (ANN) have been used for modeling the head and power characteristics on pump mixer. The trained and frozen ANN model has been used to generate head and power characteristics [20].

This paper introduce a full model of static VAR Compensator (SVC) using adaptive artificial neural network (AANN). The studied single machine infinite bus power system, with local load is solved for a different operating conditions to obtain a large number of data for training the Adaptive artificial neural network. Two different types of fault for three operating conditions is considered when collecting the data. Different ANN model for the whole system is applied to select the suitable neural network structure. The internal recurrence neural network function is employed. The studied system is represented by a set of nonlinear algebraic and differential equations. To evaluate the proposed model, the studied power system is simulated with the classical SVC and the proposed SVC based AANN model for a wide range of operating conditions. The comparative study proves the superiority of the proposed AANN excitation model over the classical one. The advantages of the proposed SVC based AANN model obtained due to the adaptive function which track the system response related to the output response. The obtained model can be used to increase the accuracy of the SVC performance 
in case of normal operating conditions as well as in case of abnormal conditions. The Matlab software is used to model and solve the studied system equation.

\section{Studied System For Feasibility Study}

The studied power system is shown in Fig. 1. The system data is given in [21]. The system consists of a synchronous generator connected to an infinite bus power system with local load and static VAR compensator.

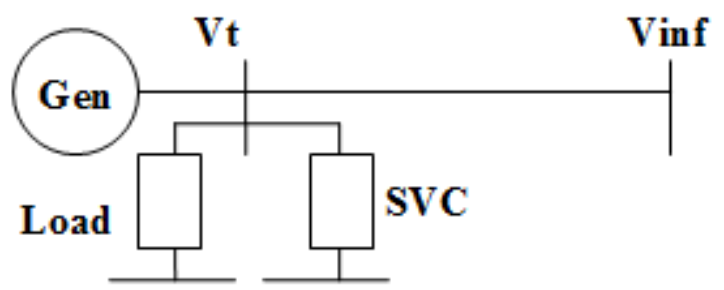

Fig. 1 Studied Power System with SVC

\section{Studied System Modeling}

\subsection{Synchronous Machine Model}

A Two-Axis dynamic model [22] has been used in this study. The system dynamic Equations are given by:

$$
\begin{aligned}
& \dot{\delta}=\omega-\omega_{\mathrm{S}} \\
& M \dot{\omega}=T_{M}-\left[E_{q}^{\backslash}-X_{d}^{\backslash} i_{d}\right] i_{q}-\left[E_{d}^{\backslash}-X_{q}^{\backslash} i_{q}\right] i_{d}-D\left(\omega-\omega_{s}\right) \\
& \mathrm{T}_{\mathrm{do}}^{\backslash} \dot{E}_{q}^{\backslash}=-E_{q}^{\backslash}-\left(\mathrm{X}_{\mathrm{d}}-\mathrm{X}_{\mathrm{d}}^{\backslash}\right) \mathrm{i}_{\mathrm{d}}+\mathrm{E}_{\mathrm{fd}} \\
& \mathrm{T}_{\mathrm{qo}}^{\prime} \dot{E}_{d}^{\prime}=-\dot{E_{d}^{\prime}}-\left(\mathrm{X}_{\mathrm{q}}-\mathrm{X}_{\mathrm{q}}^{\prime}\right) \mathrm{i}_{\mathrm{q}}
\end{aligned}
$$

\subsection{Exciter Model}

In this study, The IEEE Type DC-1 Exciter [23] has been used and shown in Fig. 2. The dynamic equations for this exciter are given by:

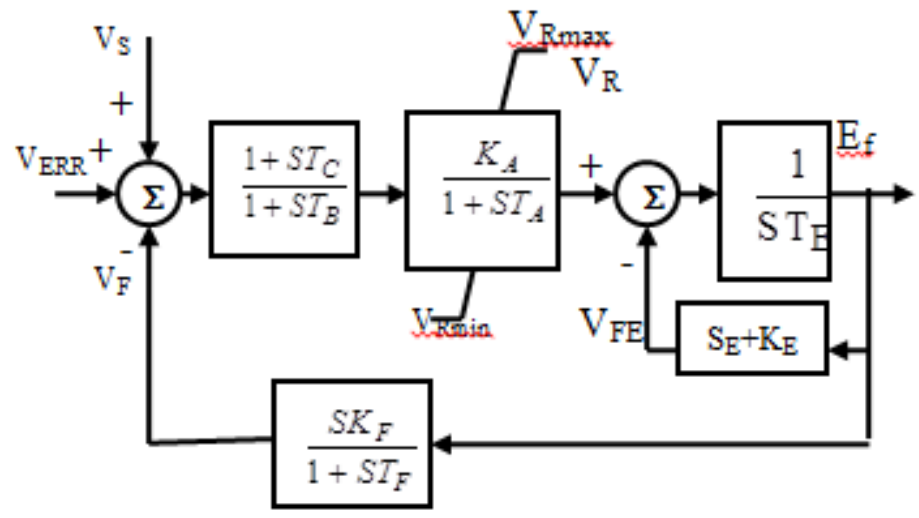

Fig. 2 Type 1 IEEE static Excitation system

$$
\begin{aligned}
& \mathrm{T}_{\mathrm{E}} \dot{\mathrm{E}}_{\mathrm{fd}}=-\left(\mathrm{K}_{\mathrm{E}}+\mathrm{S}_{\mathrm{E}}\left(\mathrm{E}_{\mathrm{fd}}\right)\right) \mathrm{E}_{\mathrm{fd}}+\mathrm{V}_{\mathrm{R}} \\
& \mathrm{T}_{\mathrm{A}} \dot{\mathrm{V}}_{\mathrm{R}}=-\mathrm{V}_{\mathrm{R}}+\mathrm{K}_{\mathrm{A}} \mathrm{R}_{\mathrm{f}}-\frac{\mathrm{K}_{\mathrm{A}} \mathrm{K}_{\mathrm{f}}}{\mathrm{T}_{\mathrm{f}}} \mathrm{E}_{\mathrm{fd}}+\mathrm{K}_{\mathrm{A}}\left(\mathrm{V}_{\mathrm{ref}}-\mathrm{V}_{\mathrm{t}}\right)
\end{aligned}
$$




$$
\mathbf{T}_{\mathbf{F}} \dot{\mathbf{R}}_{\mathrm{f}}=-\mathbf{R}_{\mathrm{f}}+\frac{\mathbf{K}_{\mathrm{f}}}{\mathbf{T}_{\mathrm{f}}} \mathbf{E}_{\mathrm{fd}}
$$

The algebraic equations are:

$$
\begin{aligned}
& 0=\left(\mathrm{R}_{\mathrm{s}}+\mathrm{R}_{\mathrm{e}}\right) \mathrm{I}_{\mathrm{d}}-\left(\mathrm{X}_{\mathrm{q}} \backslash+\mathrm{X}_{\mathrm{e}}\right) \mathrm{I}_{\mathrm{q}}-\mathrm{E}_{\mathrm{d}}{ }^{\prime}+\mathrm{V}_{\mathrm{b}} \sin \delta \\
& 0=\left(\mathrm{R}_{\mathrm{s}}+\mathrm{R}_{\mathrm{e}}\right) \mathrm{I}_{\mathrm{q}}-\left(\mathrm{X}_{\mathrm{d}} \backslash+\mathrm{X}_{\mathrm{e}}\right) \mathrm{I}_{\mathrm{d}}-\mathrm{E}_{\mathrm{q}}^{\backslash}+\mathrm{V}_{\mathrm{b}} \cos \delta \\
& \mathrm{V}_{\mathrm{t}}=\left(\mathrm{V}_{\mathrm{d}}^{2}+\mathrm{V}_{\mathrm{q}}^{2}\right)^{1 / 2} \\
& \mathrm{~V}_{\mathrm{d}}=\mathrm{R}_{\mathrm{e}} \mathrm{I}_{\mathrm{d}}-\mathrm{X}_{\mathrm{e}} \mathrm{I}_{\mathrm{q}}+\mathrm{V}_{\mathrm{b}} \sin \delta \\
& \mathrm{V}_{\mathrm{q}}=\mathrm{R}_{\mathrm{e}} \mathrm{I}_{\mathrm{q}}-\mathrm{X}_{\mathrm{e}} \mathrm{I}_{\mathrm{d}}+\mathrm{V}_{\mathrm{b}} \cos
\end{aligned}
$$

\section{Static VAR Compensator (SVC) Conventional Model}

\subsubsection{Static VAR Model}

The static Var compensator has many different models presented by literatures [24]. In this paper the used SVC is consisted of Fixed Capacitor and Thyristor Controlled reactor, ( FC-TCR) Type as shown in Fig. 3. The firing angle $\alpha$ of the reactor thyristor can be controlled using the proposed controller. It's currents are related to the firing angles by the following equations:

$$
\mathrm{I}_{\mathrm{L}}(\alpha)=\frac{\mathrm{V}(2 \pi-2 \alpha+\sin 2 \alpha)}{\pi \omega \mathrm{L}}
$$

where $\pi / 2 \leq \alpha \leq \pi$

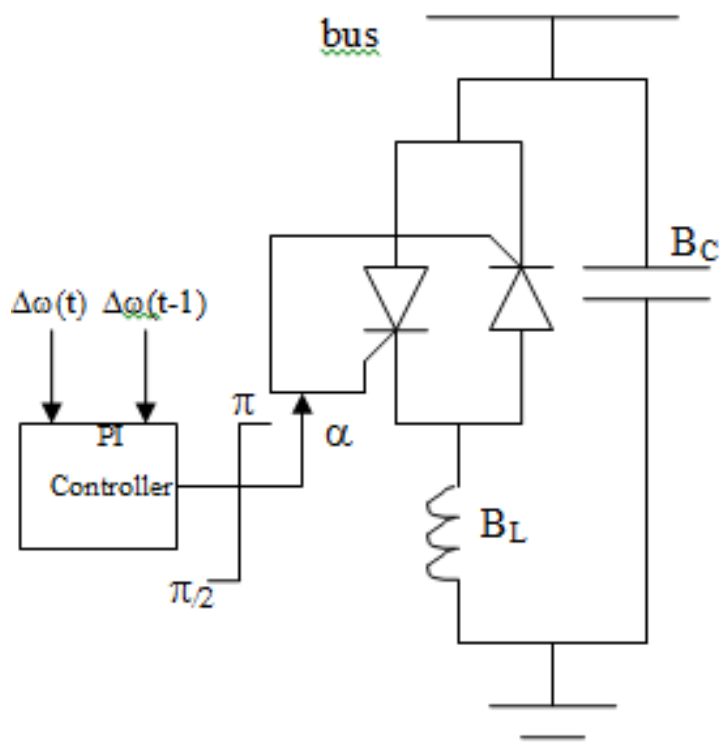

Fig. 3 Schematic Diagram of FC-TCR SVC type

$$
\mathbf{I}_{\mathbf{L}}(\sigma)=\frac{\mathrm{V}(\sigma-\sin \sigma)}{\pi \omega \mathbf{L}}
$$

From the above equation the reactor virtual susceptance can be expressed as:

$$
\mathbf{B}_{L}(\sigma)=\frac{I_{L}(\sigma)}{V}
$$

from equations (9) and (10) the susceptance can be expressed as:

$$
\mathrm{B}_{\mathrm{L}}(\sigma)=\frac{\sigma-\sin \sigma}{\pi \omega \mathrm{L}}
$$

The overall SVC susceptance is given by the summation of the fixed capacitor susceptance and the thyristor controlled variable reactor susceptance, which expressed as:

$$
\mathrm{B}_{\mathrm{SVC}}=\mathrm{B}_{\mathrm{c}}+\mathrm{B}_{\mathrm{L}}(\sigma)
$$


The conduction angle $\sigma$ and the firing angle $\alpha$ are related by the following equation:

$\sigma=2(\pi-\alpha)$

\section{SVC Model Based Adaptive Artificial Neural Network}

\subsection{Neural Network Model of static VAR compensator}

To demonstrate an adaptive artificial neural network AANN model of the static VAR compensator (SVC), different operating conditions, different fault duration and different fault types are considered to obtain the studied power system performance data. The data obtained is machine terminal voltages magnitude, angle deviations, speed deviation, and thyristor control angle $(\alpha)$. The AANN consists of input, hidden and output layers. The input signals are voltages, speed deviation, angle deviations and thyristor control angle $(\alpha)$. and the output signals is positive or negative reactive power.

\subsection{Initialize the Neural Network Data}

The proposed SVC based AANN model consists of three layers, named input layers, hidden layer and output layer. The input layer has eight nodes, the hidden layer is four nodes with nonlinear tansigmoid function and the output layer is one node. The try and error is applied to construct the best network through the dynamic performance. The AANN structure is shown in Fig. 4. The operation of such AANN can be described as follows[25].

1. The input layer nodes receive the data from the studied power system.

2. The output signals from the input nodes passes to hidden nodes via the weighed links which can be gained or attenuate.

3. Output signals from the hidden nodes result from the input signals passing through their tansigmoid activation function.

4. Hidden layer output signals are sent to output nodes through weighted connections between the hidden nodes and the output nodes.

5. The ANN output signal is obtained using tansigmoid transfer function of the output node. 


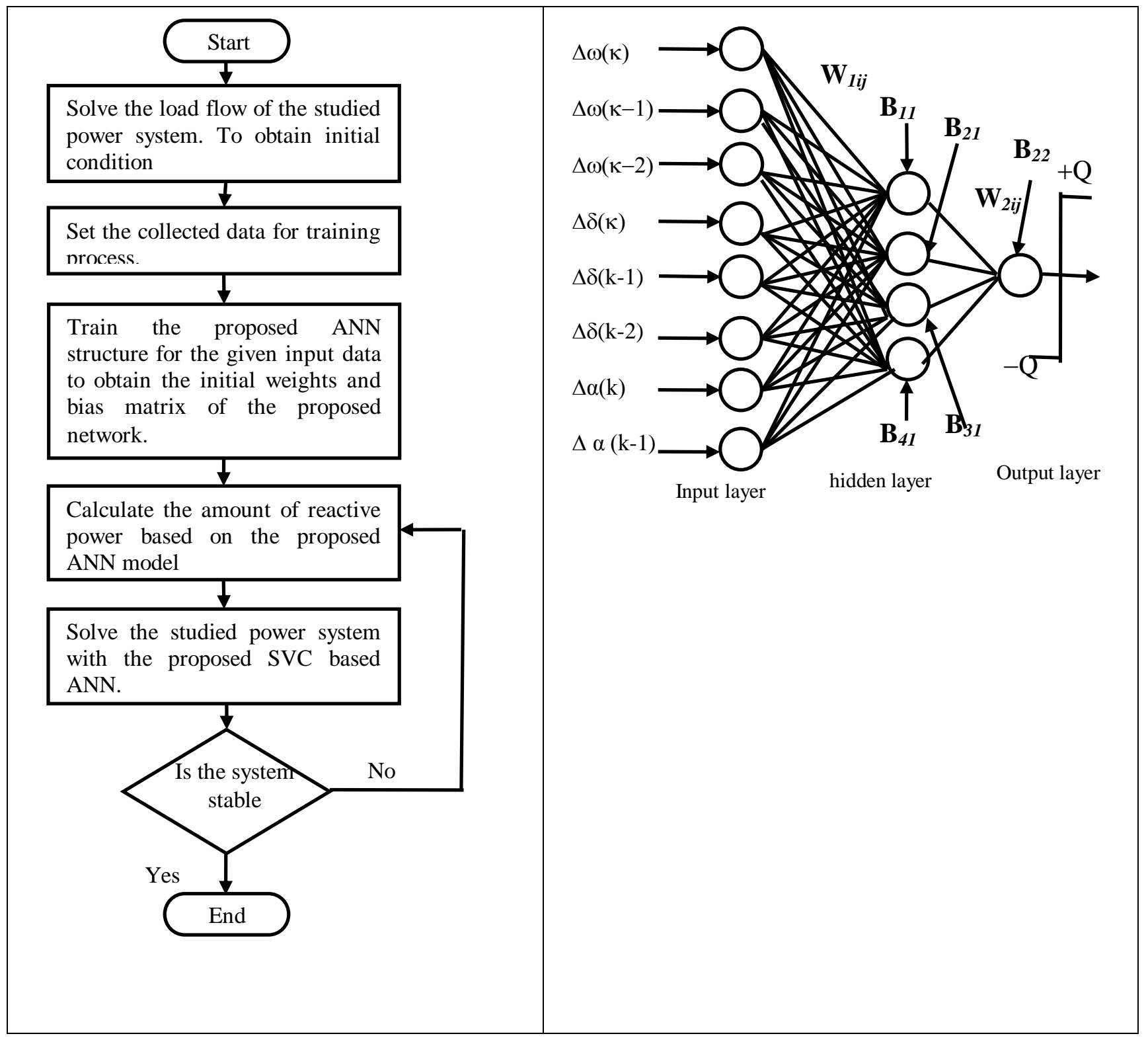

Fig. 5 Flowchart of Solving the studied power system with SVC based AANN Model.

Fig. 4 Artificial Neural Network Model of SVC

The ANN desired output signal is the amount of positive or negative reactive power to the network, where the voltage is considered to be constant value of 1.00 p.u.. The statistical data of the AANN training are as follows:

No. of training data $=6000$

No. of iterations $=6000$

Sum Squared Error $=0.001$

Learning rate $=0.001$

Momentum constant $=0.96$

FINAL NETWORK VALUES:

$\begin{array}{rlllllllll}\mathrm{W} 1= & 0.0965 & 0.2382 & -0.0610 & 0.2182 & -0.4090 & -0.2441 & 0.3329 & -0.4864 \\ -0.4334 & 0.1925 & -0.1420 & 0.2269 & -0.0459 & -0.2391 & 0.4052 & -0.4129 \\ & -0.1414 & -0.4506 & -0.3747 & -0.0206 & 0.2383 & 0.4015 & -0.2894 & 0.1565 \\ & 0.1680 & -0.0537 & 0.2233 & 0.0721 & 0.4950 & -0.3314 & -0.3227 & -0.3832\end{array}$




$$
\begin{aligned}
& \mathrm{B} 1= 0.5746 \\
&-0.5403 \\
&-0.5452 \\
& 0.8264
\end{aligned}
$$

$\mathrm{W} 2=-0.1240 \quad-0.3041 \quad-0.3556 \quad-0.2804 \quad \mathrm{~B} 2=-0.2333$

\subsection{Online Adaptive Neural Network Based SVC}

The input layers receives $\Delta \omega(\mathrm{k}), \Delta \omega(\mathrm{k}-1), \Delta \omega(\mathrm{k}-2), \Delta \delta(\mathrm{k}), \Delta \delta_{\mathrm{t}}(\mathrm{k}-1), \Delta \delta_{\mathrm{t}}(\mathrm{k}-2), \Delta \alpha(\mathrm{k}), \Delta \alpha(\mathrm{k}-1)$. The back propagation learning algorithm is an interactive method employing the gradient decent algorithm for minimizing the mean square error between the actual output and the target for each pattern in the training set. The back propagation algorithm can be discussed in the following steps:

1. Initializing the network bias and weight matrix by any values or zeros.

2. Calculate the actual output of the network layers.

3. Update the network weights in a recursive algorithm starting from the output layer and working backward to the first hidden layer. The weights and biases are updated as:

$$
\begin{aligned}
w_{i j}(\mathrm{t}+1)= & w_{i j}(\mathrm{t})+\Delta w_{i j}(\mathrm{t}) \\
\theta_{j}(\mathrm{t}+1) & =\theta_{j}(\mathrm{t})+\Delta \theta_{j}(\mathrm{t})
\end{aligned}
$$

Where:

$$
\begin{aligned}
\Delta w_{i j}(\mathrm{t}) & =\mu \delta_{\mathrm{jp}} \mathrm{O}_{\mathrm{jp}}+\beta \Delta w_{i j}(\mathrm{t}-1 \\
\Delta \theta_{j}(\mathrm{t}) & =\mu \delta_{\mathrm{jp}}(\mathrm{t})+\beta \Delta \theta_{j}(\mathrm{t}-1)
\end{aligned}
$$

4. If $\mathrm{j}$ is an output layer, then the error will be:

$$
\delta_{\mathrm{jp}}=\mathrm{F}\left(a_{j p}\right) *\left(\mathrm{~T}_{\mathrm{jp}}-\mathrm{O}_{\mathrm{jp}}\right)
$$

5. If $\mathrm{j}$ is a hidden layer then the error will be :

$$
\delta_{\mathrm{jp}}=\mathrm{F}\left(a_{j p}\right) * \sum \delta_{\mathrm{jp}} w_{i j}
$$

6. Check the error goal. If the condition is valid keep the recent data of the control system, otherwise start from the beginning. 

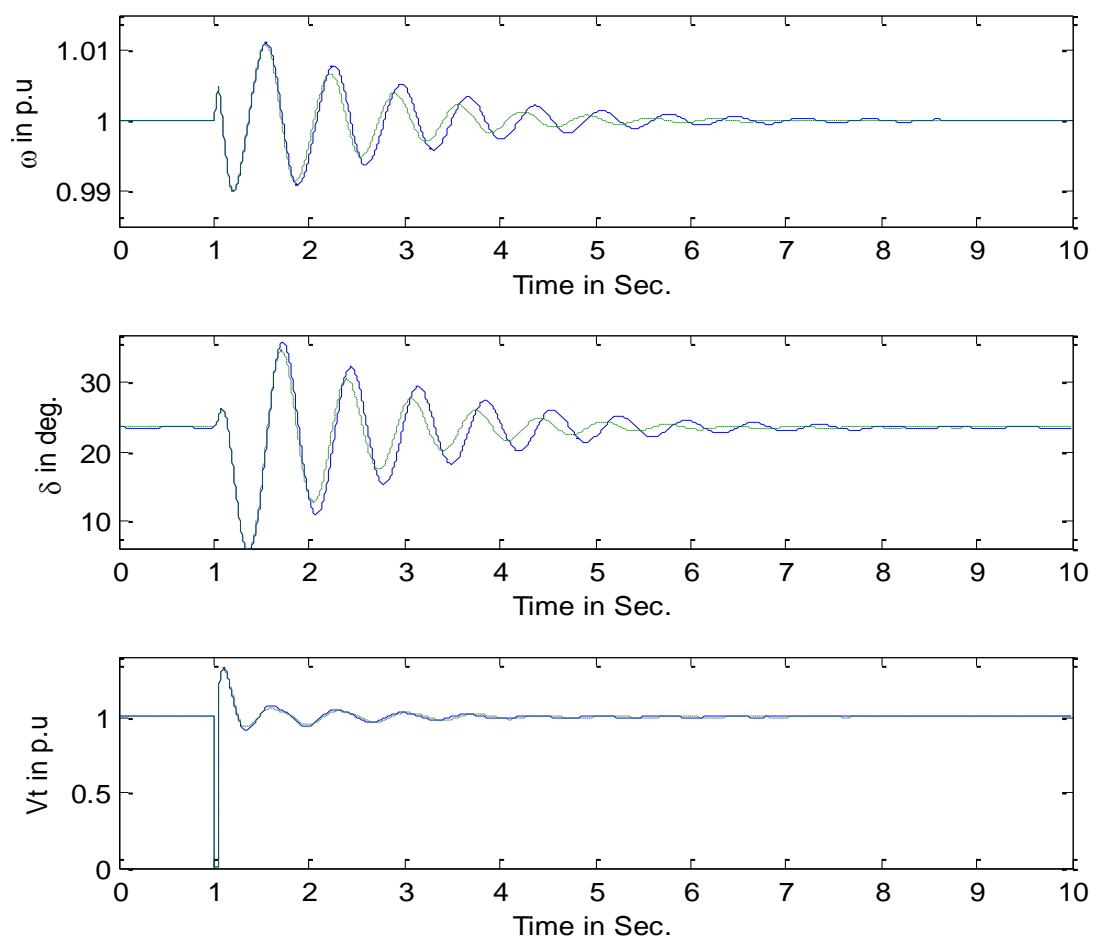

Fig. 6 Studied system dynamic performance with conv. SVC and proposed SVC based AANN model in case of 3-ph short circuit fault ( _ conv. SVC -.-. proposed model)

\section{Results and Discussion}

The flowchart discussing solving the current studied system is as shown in Fig. 5. Two cases are studied to indicate the effectively of the proposed SVC based AANN model as follows:

\subsection{Three-phase to ground fault}

A 3-ph To ground fault has been considered for $100 \mathrm{~m} . \mathrm{sec}$ at the generator terminal. The effect of the conventional SVC on the system performance and the effect of the proposed SVC based AANN model is as shown in Fig. 6. The comparative study proves the superiority of the proposed SVC based AANN model over the conventional one. I t can damp the 0scillation very fast than the conventional one.

\subsection{Input Mechanical Disturbance Fault}

An input mechanical disturbance fault with increase of $20 \%$ for $2 \mathrm{sec}$ has been proposed. The effect of the conventional SVC on the system performance and the effect of the proposed SVC based AANN model is as shown in Fig. 7. The comparative study proves the superiority of the proposed SVC based AANN model over the conventional one. I t can damp the 0scillation very fast than the conventional one. 

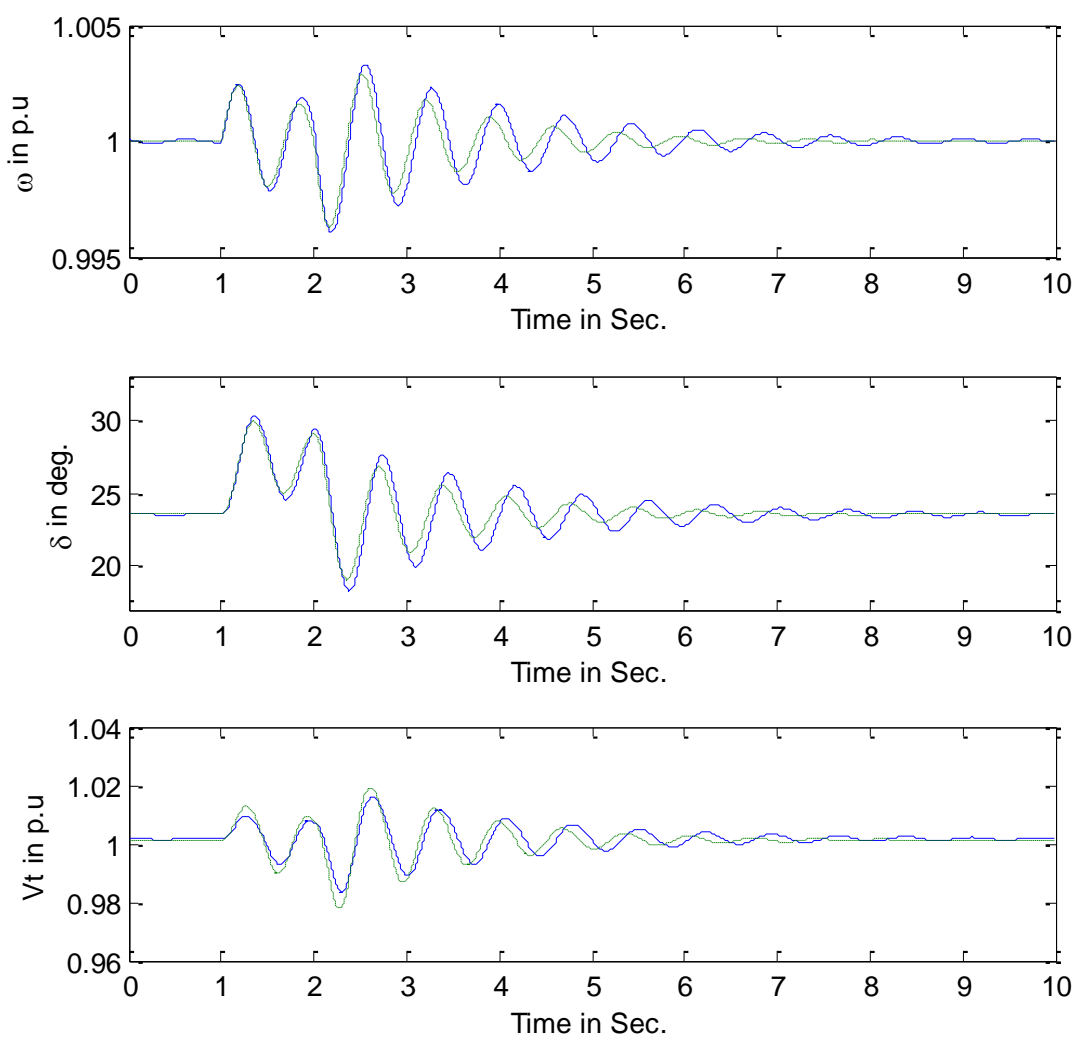

Fig. 7 Studied system dynamic performance with conv. SVC and proposed SVC based AANN model in case of input mechanical fault ( conv. SVC -.-. proposed model)

\section{Conclusions}

This paper propose an adaptive artificial neural network model for the static VAR Compensators (SVC). The structure of the proposed model is obtained through training a large number of data from the studied system for a wide range of operating conditions, different fault duration and different types of fault to ensure a well structure Network. The proposed ANN is constructed from 8 nodes in the input layer, four nodes in the hidden layers and one node at the output layer. The offline training process provides the initial data of the network, hence the adaptive function is applied to update the weights and bias matrix to follow the studied system response. The studied system is modeled using nonlinear algebraic and differential equations. The Matlab program is used for the training process and solving the system. The time simulation proved that the proposed SVC based AANN has better performance than that conventional SVC with less overshoot and under shoot.

\section{References}

[1] M. Z. El Sadek, " Prevention Measure for Voltage Collapses and Voltage Failure in The Egyptian Power Systems," Electric Power Systems Research Journal, Vol. 44, 1988, pp. 203-211.

http://dx.doi.org/10.1016/S0378-7796(97)01200-5

[2] Slaven Kincic, et al "Voltage Support by Distributed Static VAR Systems (SVS)" IEEE Trans. On Power Delivery, Vol. 2, No. 2, April, 2005, pp. 1541-1549. http://dx.doi.org/10.1109/TPWRD.2004.838640

[3] Thomas L. Baldwin, at al, "Reactive-Power Compensation for Voltage Control at Resistance Welders" IEEE Trans. On Industry Applications, Vol. 41, No. 6, Nov./Dec. 2005, pp. 1485-1492.

http://dx.doi.org/10.1109/TIA.2005.858301 
[4] M. K. Verma, S. C. Srivastava, "Optimal Placement of SVC for Static and Dynamic Voltage Security Enhancement" International Journal of Emerging Electric Power Systems Volume 2, Issue 2, 2005 Article 1050.

http://dx.doi.org/10.2202/1553-779x.1050

[5] A.H.M.A. Rahim, E.P. Nowicki, O.P. Malik, "Enhancement of power system dynamic performance through an on-line self-tuning adaptive SVC controller" Electric Power Systems Research Journal (76) 2006, pp. 801-807.

[6] A M Sharaf, M Z El-Sadek, F N Abd-Elbar and A M Hemeida,"A Global Dynamic Error Driven Control Scheme For Static VAR Compensators", Electric Power Systems Research Journal, Vol. 51, 1999, pp.131-141.

http://dx.doi.org/10.1016/S0378-7796(98)00147-3

[7] Keyhani, A, Lu, W., Heydt, G.T., "Composite neural network load models for power system stability analysis" IEEE PES Power Systems Conference and Exposition, 10-13 Oct. 2004, Vol. 2, pp. 1159-1163.

http://dx.doi.org/10.1109/psce.2004.1397702

[8] Tulpule, P., Feliachi, A., "Online Learning Neural Network based PSS with Adaptive Training Parameters" IEEE Power Engineering Society General Meeting, 24-28 June 2007, pp. 1 - 5.

[9] A.Y. Abdelaziz, M.A.L. Badr, A.H. Younes, "Dynamic load modeling of an Egyptian primary distribution system using neural networks", International Journal of Electrical Power \& Energy Systems, Volume 29, Issue 9, November 2007, pp. 637-649.

http://dx.doi.org/10.1016/j.ijepes.2006.09.006

[10] V. Leonardo Paucar, Marcos J. Rider, "Artificial neural networks for solving the power flow problem in electric power systems" Electric Power Systems Research, Volume 62, Issue 2, 28 June 2002, pp. 139-144.

http://dx.doi.org/10.1016/S0378-7796(02)00030-5

[11]P.K. Modi, S.P. Singh, J.D. Sharma, "Loadability margin calculation of power system with SVC using artificial neural network" Engineering Applications of Artificial Intelligence, Vol. 18, Issue 6, Sept. 2005, pp. 695-703.

http://dx.doi.org/10.1016/j.engappai.2005.01.006

[12] Moura, F.A.M.; Camacho, J.R., Resende, J.W., Mendes, W.R., "Synchronous generator, excitation and speed governor modeling in ATP-EMTP for interconnected DG Studies" 18th International Conference on Electrical Machines, 6-9 Sept. 2008, pp. $1-6$.

http://dx.doi.org/10.1109/icelmach.2008.4800246

[13] Hamed Shakouri G., Hamid Reza Radmanesh," Identification of a continuous time nonlinear state space model for the external power system dynamic equivalent by neural networks" International Journal of Electrical Power \& Energy Systems, Volume 31, Issues 7-8, September 2009, pp.334-344.

[14] L.A. Dobrzański, J. Trzaska, A.D. Dobrzańska-Danikiewicz, "Use of Neural Networks and Artificial Intelligence Tools for Modeling, Characterization, and Forecasting in Material Engineering" Comprehensive Materials Processing, Volume 2, 2014, pp.161-198.

http://dx.doi.org/10.1016/B978-0-08-096532-1.00215-6

[15] Ehsan Amirian, Juliana Y. Leung, Stefan Zanon, Peter Dzurman, " Integrated cluster analysis and artificial neural network modeling for steam-assisted gravity drainage performance prediction in heterogeneous reservoirs", Expert Systems with Applications 42 (2015) 723-740.

http://dx.doi.org/10.1016/j.eswa.2014.08.034

[16] Siao Sun, Hexiang Yan, Gislain Lipeme Kouyi, "Artificial neural network modelling in simulation of complex flow at open channel junctions based on large data sets", Environmental Modelling \& Software 62 (2014) 178e187.

http://dx.doi.org/10.1016/j.envsoft.2014.08.026

[17] M. Mohanraj , S. Jayaraj, C. Muraleedharan, " Applications of artificial neural networks for thermal analysis of heat exchangers - A review" International Journal of Thermal Sciences 90 (2015) 150-172.

http://dx.doi.org/10.1016/j.ijthermalsci.2014.11.030

[18] Ana Anastasijevic, Duska Coja, Natasa Neskovic, Aleksandar Neskovic,Djuradj Budimir, " Joint power amplifier and I/Q modulator impairments modeling and compensation for LTE transmitters using artificial neural networks" Int. J. Electron. Commun. (AEÜ) 69 (2015) 529-538.

http://dx.doi.org/10.1016/j.aeue.2014.11.005 
[19] J. Sargolzaei, A. Kianifar, "Modeling and simulation of wind turbine Savonius rotors using artificial neural networks for estimation of the power ratio and torque", Simulation Modelling Practice and Theory 17 (2009) 1290-1298 http://dx.doi.org/10.1016/j.simpat.2009.05.003

[20] K.K. Singh, K.T. Shenoy, A.K. Mahendrab, S.K. Ghosh, " Arti cial neural network based modelling of head and power characteristics of pump-mixer" Chemical Engineering Science 59 (2004) 2937 - 2945

http://dx.doi.org/10.1016/j.ces.2004.04.025

[21]P. Shamsollahi, and 0 . P. Malik, "An Adaptive Power System Stabilizer Using On-Line Trained Neural Networks" IEEE Transactions on Energy Conversion, Vol. 12, No. 4, pp. 382-387, December 1997. http://dx.doi.org/10.1109/60.638951

[22] Sauer Peter W., and M. A. Pai, "Power System Dynamics and Stability", Book, Prentice Hall, Inc., 1998.

[23] IEEE Committee Report, "Excitation System Models for Power System Stability Studies" IEEE Transactions on Power Apparatus and Systems, Vol. PAS-100, Issue 2, pp. 494 - 509, Feb.,1981.

[24]Fernando Cattan Jusan, Sergio Gomes Jr, Glauco Nery Taranto," SSR results obtained with a dynamic phasor model of SVC using modal analysis", Electrical Power and Energy Systems 32 (2010) 571-582.

http://dx.doi.org/10.1016/j.ijepes.2009.11.013

[25]M. K. El-Sherbiny, G. El-Saady, E. A. "Speed deviation deriven adaptive neural network based power system stabilizer" Electric Power Systems Research Journal, Vol. 38, 1996, pp. 169-175.

http://dx.doi.org/10.1016/S0378-7796(96)01079-6 